\title{
LINHAGENS DIAPLÓIDES DE TRIGO: DESEMPENHO AGRONÔMICO EM DOIS LOCAIS DO ESTADO DE SÃO PAULO E TOLERÂNCIA À TOXICIDADE DE ALUMÍNIO EM LABORATÓRIO $\left({ }^{(1)}\right.$
}

\author{
CARLOS EDUARDO DE OLIVEIRA CAMARGO $\left({ }^{2,8}\right)$; ANTONIO WILSON PENTEADO FERREIRA FILHO $\left({ }^{2}\right)$; \\ JOÃO CARLOS FELICIO $\left({ }^{2}\right)$; LUÍS CARLOS DA SILVA RAMOS $\left({ }^{3}\right)$; ARMANDO PETTINELLI JUNIOR $\left({ }^{4}\right)$; \\ DULCINÉIA ELIZABETE FOLTRAN $\left({ }^{5}\right)$; JAIRO LOPES DE CASTRO $\left({ }^{6}\right)$; MARY TÚLIA VARGAS LOBATO $\left({ }^{7}\right)$.
}

\begin{abstract}
RESUMO
Foram avaliados 20 genótipos (18 linhagens diaplóides e as cultivares IAC-24 e IAC-370) de trigo em ensaios instalados em condição de sequeiro e solo ácido em Capão Bonito e em condição de irrigação por aspersão e solo corrigido em Tatuí, no período 2001-2003. A produção de grãos, outros componentes da produção, características agronômicas e resistência às doenças foram analisados. Estudou-se também a tolerância à toxicidade de alumínio em soluções nutritivas, em laboratório. A cultivar IAC-24 e as linhagens diaplóides L3, L4, L5, L8, L14, L15, L16, L17, L18, L19 e L20, em Capão Bonito, destacaram-se quanto à produção de grãos, e em soluções nutritivas, foram as mais tolerantes à toxicidade de alumínio. Todos os genótipos exibiram porte semi-anão. As linhagens diaplóides L15 e L16 foram resistentes ao acamamento; na cultivar IAC-370 observaram-se espigas mais compridas e maior número de grãos por espiga e por espigueta, na L8 o maior número de espiguetas por espiga e na L6 e L7, os grãos mais pesados. Todos os genótipos avaliados foram suscetíveis à mancha-da-folha. As linhagens L4, L14, L15, L16, L17 e L18 oriundas do cruzamento R27/GHL121//KAL/BB/3/BUC/BUL/4/IAC-24 foram resistentes à ferrugem-da-folha. Os genótipos mais produtivos em condição de sequeiro e solo ácido sem aplicação de calcário foram associados a plantas de porte semi-anão mais altas, exibindo tolerância à toxicidade de alumínio. Em solo corrigido e com irrigação por aspersão, os genótipos mais produtivos não estavam associados às plantas altas, com porte semi-anão, nem à tolerância ao alumínio.
\end{abstract}

Palavras-chave: Triticum aestivum L, produção de grãos, altura das plantas, componentes da produção, resistência às doenças.

$\left.{ }^{1}\right)$ Trabalho parcialmente financiado pela FAPESP. Apresentado no $3 .^{\circ}$ Congresso Brasileiro de Melhoramento de Plantas, realizado em Gramado (RS), em 2005. Recebido para publicação em 17 de maio de 2005 e aceito em 28 de abril de 2006.

$\left(^{2}\right)$ Instituto Agronômico (IAC), Centro de Análise e Pesquisa Tecnológica do Agronegócio de Grãos e Fibras, Caixa Postal 28, 13001-970 Campinas (SP). Autor correspondente: E-mail: ccamargo@iac.sp.gov.br.

$\left(^{3}\right)$ Centro de Recursos Genéticos Vegetais, Instituto Agronômico (IAC).

$\left({ }^{4}\right)$ Unidade de Pesquisa do Desenvolvimento de Tatuí, Caixa Postal 33, 18270-000 Tatuí (SP).

$\left({ }^{5}\right)$ Unidade de Pesquisa do Desenvolvimento de Tietê, Caixa Postal 18, 18530-970 Tietê (SP).

${ }^{6}$ ) Pólo Regional de Desenvolvimento Tecnológico dos Agronegócios do Sudoeste Paulista, Caixa Postal 62, 18300-970, Capão Bonito (SP).

$\left({ }^{7}\right)$ Bolsista de mestrado da CAPES.

$\left({ }^{8}\right)$ Com bolsa de produtividade em pesquisa do CNPq. 


\title{
ABSTRACT \\ WHEAT DIHAPLOID LINES: AGRONOMIC BEHAVIOUR IN TWO LOCATIONS OF THE STATE OF SÃO PAULO AND TOLERANCE TO ALUMINUM TOXICITY IN LABORATORY
}

\begin{abstract}
Twenty wheat genotypes (18 dihaploid lines and the IAC-24 and IAC-370 cultivars) were evaluated in experiments carried out under dryland and acid soil conditions in Capão Bonito and under sprinkler irrigation and limed soil conditions in Tatuí in 2001-03 period. Grain yield, yield components, agronomic characteristics and disease resistance were evaluated. The genotypes were also evaluated for their tolerance to Al toxicity, in nutrient solutions, under laboratory conditions. IAC-24 and the dihaploid lines L3, L4, L5, L8, L14, L15, L16, L17, L18, L19 e L20, in Capão Bonito, were superior for grain yield. In nutrient solutions, these were the most tolerant genotypes to aluminum toxicity. All genotypes exhibited semi-dwarf plant type. The dihaploid line L15 and L16, presented lodging resistance, IAC-370 longer spikes and higher number of grain per spike and per spikelet, L8 higher number of spikelets per spike and L6 and L7 the heavier grains. All evaluated genotypes were susceptible to leaf spot. The lines L4, L14, L15, L16, L17 and L18 originated from the cross R27/GHL121//KAL/BB/3/BUC/BUL/4/IAC-24 showed resistance to leaf rust. The higher grain yield genotypes, under dryland and acid soil conditions, were associated to taller semi-dwarf plants with tolerance to aluminum toxicity. Under sprinkler irrigation and limed soil conditions the highest yielding genotypes were not associated to either semi-dwarf plants or those tolerant to aluminum toxicity.
\end{abstract}

Key words: Triticum aestivum L, grain yield, plant height, yield components, disease resistance.

\section{INTRODUÇÃO}

O Brasil depende da importação de grãos de trigo para atender sua demanda por farinha para as mais diversas finalidades. Em 2004 o país produziu cerca de 6 milhões de toneladas desse grão necessitando, portanto, importar ainda 4 milhões para garantir o consumo interno.

Assim, a obtenção de genótipos de trigo que melhor se adaptem às condições edafoclimáticas paulistas e o desenvolvimento de técnicas de produção que visem à redução dos custos são de grande importância para minimizar a dependência externa.

O programa de melhoramento de trigo do Instituto Agronômico (IAC) busca desenvolver cultivares de porte semi-anão, com alto potencial produtivo e tolerantes à toxicidade de alumínio, mediante cruzamentos entre cultivares nacionais adaptadas às condições de solo ácido e genótipos semi-anões com alto potencial produtivo, originários do Centro Internacional de Melhoramento de Milho e Trigo (CIMMYT), México (CAMARgo et al., 1990; 1991).

No processo convencional de melhoramento de plantas autógamas, após o cruzamento, são necessárias sete a nove gerações de autofecundação para se obter estabilidade fenotípica, representada por um alto grau de homozigose. Visando reduzir o tempo de obtenção de novas cultivares, novas técnicas têm sido incorporadas ao programa de melhoramento, entre as quais a técnica da cultura de anteras "in vitro". Com essa técnica, obtêm-se plantas haplóides, que podem se tornar férteis após a duplicação do número de cromossomos utilizando-se colchicina. As plantas obtidas com base nesse tratamento apresentam $100 \%$ de homozigose, sendo convencionalmente consideradas diaplóides (DH). Essa técnica é muito valiosa nos programas de melhoramento genético, visto que a homozigose é alcançada em apenas uma geração (GRANDO e MorAesFernandes, 1997; CAmARgo et al., 2001; SAlOMON et al., 2003). Após a adaptação da técnica (RAmos et al., 1994), as primeiras linhagens DH de trigo foram obtidas no IAC (CAMARGO et al., 1999).

O emprego da técnica de obtenção de linhagens $\mathrm{DH}$ tem sido altamente eficiente, tendo originado novos genótipos de trigo com características agronômicas vantajosas, em um período menor, em relação ao programa de melhoramento tradicional (CAmARgo et al., 2003; SALOMOn et al., 2003).

O objetivo deste trabalho foi avaliar as linhagens $\mathrm{DH}$ provenientes de cruzamentos entre linhagens introduzidas do CIMMYT, México e a cultivar IAC-24, em comparação com cultivarescontrole, em experimentos instalados em dois locais do Estado de São Paulo.

\section{MATERIAL E MÉTODOS}

Os experimentos foram instalados em dois locais do Estado de São Paulo: Capão Bonito (latitude $24^{\circ} 00^{\prime} \mathrm{S}$, longitude $48^{\circ} 22^{\prime} \mathrm{W}$ e altitude $702 \mathrm{~m}$ ), em condição de sequeiro e solo ácido, e Tatuí (latitude 
$23^{\circ} 20^{\prime} \mathrm{S}$, longitude $47^{\circ} 52^{\prime} \mathrm{W}$ e altitude $600 \mathrm{~m}$ ), em condição de irrigação por aspersão e solo corrigido, durante o período de 2001 a 2003. Foram avaliados 20 genótipos, sendo 18 linhagens diaplóides, obtidas via cultura de anteras in vitro (RAmos et al., 1994), e duas cultivares-controle (Tabela 1).

Nos experimentos de campo, usou-se o delineamento experimental de blocos ao acaso, com quatro repetições por local. O experimento constituiuse de 80 parcelas, cada uma delas formada por seis linhas de $3 \mathrm{~m}$ de comprimento, espaçadas de $0,20 \mathrm{~m}$ e separadas, lateralmente, por 0,60 m. A semeadura foi feita utilizando-se 80 sementes viáveis por metro de sulco, equivalendo a 1.440 sementes por parcela, com área útil de colheita de $3,6 \mathrm{~m}^{2}$.

Coletaram-se os seguintes dados nos experimentos: ciclo da emergência ao florescimento e da emergência à maturação somente dos ensaios instalados em Capão Bonito; ocorrência de acamamento; altura das plantas e produção de grãos. Para determinar o comprimento da espiga, o número de espiguetas, o número de grãos por espiga e por espigueta e a massa de cem grãos, foram tomadas cinco espigas de cada parcela, apenas no experimento de Tatuí em 2002. A avaliação dessas características foi feita conforme CAMARGO et al. (1995).

Os dados de produção de grãos, altura das plantas, ciclos da emergência ao florescimento e da emergência à maturação, comprimento da espiga, número de espiguetas, número de grãos por espiga e por espigueta e massa de cem grãos de cada experimento foram inicialmente submetidos às análises individuais da variância. Efetuou-se, posteriormente, a análise conjunta da variância para produção de grãos e altura da planta, nos experimentos instalados em Tatuí e Capão Bonito, e para ciclos, somente nos experimentos instalados em Capão Bonito, a fim de avaliar a ocorrência da interação dos genótipos com os anos em cada local. Para a comparação das médias dos genótipos, utilizou-se o teste de Tukey ao nível de 5\%.

Efetuou-se a avaliação da ferrugem-da-folha (Puccinia triticina), em cada parcela, em pelo menos uma repetição de cada experimento, com exceção dos experimentos de Tatuí (2001 e 2003), por observação geral, nos colmos e nas folhas superiores das plantas, no estádio de início de maturação em condições naturais de infecção. Empregou-se a escala modificada de Cobb, para avaliação da resistência, segundo Schramm et al. (1974). Essa escala vai de 0 a 99\% de área foliar infectada, complementada pelo tipo de reação: $S$ = suscetível (uredossoro grande, coalescente, sem necrose e sem clorose); MS = moderadamente suscetível (uredossoro médio); $\mathrm{M}=$ intermediário (diversos tipos de reação); $M R=$ moderadamente resistente (uredossoro pequeno); $\mathrm{R}=$ resistente (uredossoro minúsculo, rodeado de áreas necróticas). A avaliação da presença de mancha-dafolha (Bipolaris sorokiniana) também foi realizada em cada parcela, em pelo menos uma repetição de cada experimento, com exceção dos de Tatuí (2002 e 2003), pela observação geral no estádio de planta adulta, em condições naturais de infecção, empregando uma escala (Menta,1978) de 0 a 99\% de área infectada; zero é considerado imune; $1 \%$ a $5 \%$ resistente; $6 \%$ a $25 \%$ moderadamente resistente; $26 \%$ a $50 \%$ suscetível, e $51 \%$ a $99 \%$ altamente suscetível.

As plântulas dos 20 genótipos e das cultivares-controle BH-1146 (tolerante) e Anahuac (sensível) foram testadas para a tolerância ao alumínio, em condição de laboratório, nas doses de 0, 2, 4, 6, 8 e $10 \mathrm{mg} \mathrm{L}^{-1}$ de $\mathrm{Al}^{3+}$, em soluções nutritivas, conforme Camargo e Oliveira (1981), Camargo (1984) e Moore et al. (1976).

O delineamento experimental foi o de blocos ao acaso, com arranjo em parcelas subdivididas: as parcelas, compostas por seis concentrações de alumínio $(0,2,4,6,8$ e $10 \mathrm{mg}$ $\mathrm{L}^{-1}$ de $\mathrm{Al}^{3+}$ ) e as subparcelas, pelos 20 genótipos de trigo. Realizaram-se duas repetições para cada solução-tratamento. Na análise dos dados, considerou-se a média de comprimento da raiz primária central das cinco plantas de cada genótipo, para cada repetição.

Após 48 horas nas soluções de tratamento contendo as diferentes concentrações de alumínio, os genótipos foram transferidos para soluções nutritivas completas sem alumínio, por 72 horas. Aqueles que apresentaram crescimento radicular nesse meio foram considerados tolerantes, enquanto aqueles que não mostraram crescimento das raízes foram considerados sensíveis.

Calcularam-se correlações simples separadamente para os experimentos instalados em Tatuí e Capão Bonito, no período 2001-2003, entre as produções médias de grãos e as alturas médias das plantas dos 20 genótipos nesse período com os crescimentos médios das raízes dos genótipos, medidos após 72 horas de crescimento na solução nutritiva, que se seguiu ao da solução-tratamento contendo 2, 4, 6, 8 e $10 \mathrm{mg} \mathrm{L}^{-1}$ de $\mathrm{Al}^{3+}$. Foram também calculadas as correlações entre as produções médias de grãos com as alturas médias das plantas dos 20 genótipos nesse período, para os experimentos instalados nos dois locais considerados. 


\section{RESULTADOS E DISCUSSÃO}

Os quadrados médios das análises de variância individual das produções de grãos dos genótipos (linhagens diaplóides e cultivares) de trigo, estudados nos experimentos de Capão Bonito e Tatuí em 2001, 2002 e 2003 mostraram efeitos não significativos para repetição, com exceção do de Capão Bonito (2001), e significativos para genótipos (Tabela 1).

Os quadrados médios da análise conjunta da variância das produções médias dos genótipos dos experimentos de Capão Bonito (2001-2003), instalados em condição de sequeiro e de solo ácido, revelaram efeitos significativos para anos, genótipos e não significativo para a interação genótipos $\mathrm{x}$ anos (Tabela 1).

Os coeficientes de variação calculados para cada um dos ensaios instalados em Capão Bonito bem como, quando, esses ensaios analisados em conjunto foram altos (Tabela 1) indicando, portanto, a ocorrência de grandes erros experimentais. Esse fato pode ser explicado em virtude de o local estudado ter um solo originalmente ácido, nunca corrigido por calagem e, portanto, não uniforme, com variações, principalmente nos teores de alumínio e de bases (CAMARgo et al., 1997). Apesar disso, essa área experimental tem sido de grande utilidade para os trabalhos de melhoramento genético do trigo do IAC, onde são selecionadas linhagens tolerantes à toxicidade de alumínio. Mesmo com a redução da precisão dos experimentos os dados obtidos têm permitido com sucesso a separação dos genótipos mais produtivos, tolerantes à toxicidade de alumínio dos menos produtivos e sensíveis a essa toxicidade (CAMARgo et al., 1997 e 2005; SALOMON et al., 2003).

Para a comparação das médias de produção de grãos dos genótipos dos três experimentos de Capão Bonito, pelo teste de Tukey, verificou-se que as linhagens diaplóides L9, L10 e L11 com produções de grãos variando de 332 a $396 \mathrm{~kg} \mathrm{ha}^{-1}$ foram as menos produtivas, não diferindo das linhagens diaplóides L6 (527 kg ha-1), L7 (469 kg ha-1), L12 (456 kg ha $\left.{ }^{-1}\right)$ e L13 (447 kg ha $\left.{ }^{-1}\right)$, diferindo, porém, das cultivares IAC-370 (1.061 kg.ha-1) e IAC-24 (1.509 kg ha $\left.{ }^{-1}\right)$ e das demais linhagens diaplóides avaliadas. Estas foram as mais produtivas na condição de solo ácido, com produções de grãos variando de 1250 a $1627 \mathrm{~kg} \mathrm{ha}^{-1}$. Apesar do alto coeficiente de variação observado quando os três ensaios instalados em Capão Bonito foram considerados em conjunto $(33,95 \%)$ os resultados permitiram separar os genótipos mais produtivos e possivelmente com maior adaptação a essa condição de solo ácido dos genótipos menos produtivos e, portanto, com reduzida adaptação a essa condição edáfica. Resultados semelhantes foram relatados por CAMARGO et al., 1997 e SALOMON et al., 2003.

Como já considerado em outro trabalho (CAMARGo et al., 2003) as linhagens diaplóides obtidas pela duplicação de plantas haplóides, oriundas de cultura de anteras de plantas híbridas, em geração $\mathrm{F}_{1}$, permitiu um ganho de, pelo menos, cinco anos em relação ao Método Genealógico adotado pelo Instituto Agronômico (CAMARGo, 1993).

Os quadrados médios da análise da variância conjunta das produções de grãos dos genótipos avaliados nos três experimentos de Tatuí (2001-2003), utilizando-se irrigação por aspersão e solo corrigido pela calagem, mostraram-se significativos para anos, genótipos e para a interação genótipos $\mathrm{x}$ anos. Resultados semelhantes foram obtidos por CAMARGO et al. (2001), avaliando linhagens de trigo resultantes de hibridações, em Tatuí, em 1996 e 1997. Considerando-se as médias do experimento instalado em Tatuí, em 2001 (Tabela 1), a linhagem L11, com produtividade de $2.816 \mathrm{~kg} \mathrm{ha}^{-1}$, foi a melhor, diferindo, porém, somente das linhagens L3, L6, L8, L19 e L20, que foram as menos produtivas (1.496 a $\left.2.114 \mathrm{~kg} \mathrm{ha}^{-1}\right)$.

As linhagens $9\left(3.253 \mathrm{~kg} \mathrm{ha}^{-1}\right)$ e $13(3.188 \mathrm{~kg}$ $\mathrm{ha}^{-1}$ ) destacaram-se quanto à produção de grãos em Tatuí, em 2002, somente diferindo das linhagens L8, L19 e L20, as menos produtivas, com produções de grãos variando de 1.854 a $2.101 \mathrm{~kg} \mathrm{ha}^{-1}$. No experimento instalado em 2003, a cultivar IAC-370 (3.913 $\left.\mathrm{kg} \mathrm{ha}^{-1}\right)$ foi a mais produtiva, não diferindo apenas da IAC-24 (2.715 $\left.\mathrm{kg} \mathrm{ha}^{-1}\right)$ e das linhagens diaplóides L4, L9, L17 e L19 cujas produções de grãos variaram entre 2.597 e $2.931 \mathrm{~kg} \mathrm{ha}^{-1}$.

Os quadrados médios das análises de variância individual das alturas das plantas dos genótipos de trigo estudados nos experimentos de Capão Bonito e Tatuí em 2001, 2002 e 2003 revelaram efeitos não significativos para repetição, com exceção do de Capão Bonito (2001) e o de Tatuí (2002), e significativos para genótipos (Tabela 2).

Os quadrados médios da análise conjunta da variância das alturas das plantas dos genótipos dos experimentos de Capão Bonito e de Tatuí, no período 2001-2003, revelaram efeitos significativos para anos, genótipos e para a interação genótipos x anos (Tabela 2).

Considerando o experimento de Capão Bonito de 2001, verificou-se que as linhagens diaplóides L14, L15, L16 e L18 produziram as plantas com maior estatura, variando de 79 a $81 \mathrm{~cm}$, diferindo das linhagens L6, L7, L9, L10, L11, L12 e L13, que foram as mais baixas entre as avaliadas, não diferindo dos 
demais genótipos. No experimento de 2002 as linhagens L16 e L17, que exibiram altura das plantas de $84 \mathrm{~cm}$, foram as mais altas diferindo somente da cultivar IAC-370 $(60 \mathrm{~cm})$ e das linhagens L6, L7, L8, L9, L10, L11, L12 e L13, as mais baixas. A linhagem diaplóide L5 foi a mais alta em 2003, em Capão Bonito, diferindo somente das cultivares IAC-24 e IAC-370 e das linhagens diaplóides L3, L6, L7, L8, L9, L10, L11, L12 e L13, que apresentaram altura de plantas variando de 35 a $66 \mathrm{~cm}$.

A linhagem diaplóide L5 foi a mais alta nos experimentos instalados em Tatuí, nos anos de 2001, 2002 e 2003. Em 2001, a altura de planta foi de $89 \mathrm{~cm}$ e somente não diferiu da cultivar IAC-370 $(83 \mathrm{~cm}) \mathrm{e}$ das linhagens L4, L12, L14, L15, L16, L18 e L19, cujas alturas variaram de 79 a $83 \mathrm{~cm}$. No ensaio de 2002, a L5 $(96 \mathrm{~cm})$ também não diferiu da cultivar IAC-370 $(90 \mathrm{~cm})$ e das linhagens L15 e L19, diferindo das demais com porte baixo, variando de 76 a $86 \mathrm{~cm}$. Em 2003, a L5 $(83 \mathrm{~cm})$ diferiu apenas das linhagens diaplóides L7, L8, L10, L11, que foram as mais baixas, com estatura variando de 64 a $69 \mathrm{~cm}$. Linhagens diaplóides baixas também foram identificadas por SALOMON et al., 2003, em ensaios avaliados em Tatuí e Capão Bonito, em 1999 e 2000.

Os quadrados médios das análises de variância individual dos ciclos médios, em dias da emergência ao florescimento e da emergência à maturação, dos genótipos estudados nos experimentos de Capão Bonito em 2001, 2002 e 2003 revelaram efeitos não significativos para repetição, com exceção do ciclo da emergência ao florescimento de 2001 e significativos para genótipos (Tabela 3).

Os quadrados médios da análise conjunta da variância dos ciclos médios, em dias, da emergência ao florescimento e da emergência à maturação dos genótipos dos experimentos de Capão Bonito (20012003), instalados em condição de sequeiro e de solo ácido, revelaram efeitos significativos para anos, genótipos e para a interação genótipos $\mathrm{x}$ anos (Tabela 3).

As linhagens L4, L14, L15, L16, L17 e L18 foram as mais tardias para florescer bem como para maturar considerando-se individualmente os ensaios instalados em Capão Bonito, no período 2001-03. No ensaio de 2001 todas as linhagens diaplóides foram precoces para maturar com exceção de L4, L14, L15, L16, L17 e L18. Em 2002, as linhagens L6, L7, L9, L10, L11, L12, L13 e em 2003 a linhagem L3 foram as mais precoces para maturar. Linhagens tardias e precoces para florescer e maturar foram também identificadas em ensaios semeados em Capão Bonito e Tatuí, no período 1997-99 (CAMARGO et al., 2005).
As linhagens L3, L5, L6 e L7 exibiram as maiores porcentagens médias de acamamento (variando de $20 \%$ a $33 \%$ ) nos dois locais considerados. Por outro lado, L15 e L16 foram resistentes ao acamamento (nenhuma planta acamada) nos experimentos instalados nos dois locais (Tabela 4 ).

Os graus médios de infecção de mancha-dafolha e ferrugem-da-folha, nos genótipos avaliados nos experimentos de Capão Bonito e de Tatuí, são apresentados nas tabelas 5 e 6 respectivamente. Verificou-se que os graus médios de infecção de mancha-da-folha foram elevados, deduzindo que as condições ambientais eram favoráveis ao desenvolvimento do patógeno.

Empregando-se a escala proposta por Menta (1978), todos os genótipos foram classificados como suscetíveis (Tabela 5), manifestando uma porcentagem de área foliar infectada entre 26 e 50, em pelo menos, um experimento. As linhagens L3, L6, L8, L9, L12 e L20 foram altamente suscetíveis aos agentes causais das manchas foliares, com uma porcentagem de área foliar infectada entre 51 e 99 em, pelo menos, um dos experimentos avaliados. Esses resultados eram esperados, considerando-se que as 18 linhagens diaplóides avaliadas originaram-se do cruzamento entre a cultivar de trigo IAC-24 e as linhagens de origem mexicana, suscetíveis ao agente causal das manchas foliares (CAMARgo, 1993; CAMARgo e Ferreira FilHo, 2000; CAMARGO et al., 2003).

Em relação à ferrugem-da-folha (Tabela 6), as linhagens diaplóides, oriundas do cruzamento entre a cultivar IAC-24 e a linhagem mexicana R27/ GHL121//KAL/ BB/3/BUC/BUL, foram imunes (L15, L16 e L17) ou resistentes (L4, L14 e L18) (Schramm et al., 1974). Pela resistência observada (baixa severidade da doença), provinda do genitor mexicano, em todos os experimentos considerados, sugere-se que esses genótipos possam servir como fonte de resistência em programa de melhoramento visando à resistência à ferrugem-da-folha do trigo. Imunidade a essa doença também foi relatada por Lовато et al. (2005), avaliando genótipos mexicanos, sugerindo que a linhagem 5 (CNDO/R143//ENTE/ MEXI/3...) pela resistência poderia ser empregada como fonte de resistência em programas de cruzamentos.

Os demais genótipos comportaram-se como moderadamente resistentes, ou seja, com um grau de infecção entre $6 \%$ e $25 \%$, em pelo menos, um dos experimentos avaliados. Foi exceção a L3 que foi suscetível, com um grau de infecção de $30 \mathrm{~S}$ no experimento de Capão Bonito, de 2003. 
Tabela 1. Testes de médias e análises da variância individuais e conjuntas (anos) para a variável produção média de grãos, em kg ha ${ }^{-1}$, dos 20 genótipos de trigo avaliados nos Ensaios de Linhagens Provenientes de Cultura de Anteras, instalados em Capão Bonito e Tatuí, em 2001 , 2002 e 2003

\begin{tabular}{|c|c|c|c|c|c|c|c|c|c|}
\hline \multirow{2}{*}{ Genótipos } & \multirow{2}{*}{ Genealogia } & \multicolumn{3}{|c|}{ Capão Bonito } & \multicolumn{5}{|c|}{ Tatuí } \\
\hline & & 2001 & 2002 & 2003 & Média & 2001 & 2002 & 2003 & Média \\
\hline & & \multicolumn{8}{|c|}{$\mathrm{kg} \mathrm{ha}^{-1}$} \\
\hline 1 & IAC-24 & 1917 & 1517 & 1094 & 1509 a & 2194 a-d & 2913 a-c & $2715 \mathrm{ab}$ & 2608 \\
\hline 2 & IAC-370 & 1608 & 847 & 729 & $1061 \mathrm{ab}$ & $2601 \mathrm{ab}$ & 2715 a-d & 3913 a & 3076 \\
\hline 3 & $\begin{array}{l}\text { CEP83121/CEP83140/3/TJB88.1089/ALDAN/ } \\
\text { /CEP13/4/IAC-24 }\end{array}$ & 1264 & 1292 & 1194 & 1250 a & 2083 b-e & 2444 a-d & $2413 \mathrm{~b}$ & 2314 \\
\hline 4 & R27/GHL121//KAL/BB/3/BUC/BUL/4/IAC-24 & 1819 & 1677 & 1229 & 1575 a & $2351 \mathrm{a}-\mathrm{c}$ & 2615 a-d & $2597 \mathrm{ab}$ & 2521 \\
\hline 5 & MAITEN/ / BJY “S” /JUP /3 / IAC-24 & 1191 & 1431 & 1788 & 1470 a & $2371 \mathrm{a}-\mathrm{c}$ & 2368 a-d & $2118 \mathrm{~b}$ & 2286 \\
\hline 6 & GAA “S” / KAUZ “S” / / IAC-24 & 899 & 569 & 111 & $527 \mathrm{bc}$ & 1844 c-e & 2733 a-d & $2132 \mathrm{~b}$ & 2236 \\
\hline 7 & GAA “S" / KAUZ "S" / /IAC-24 & 705 & 521 & 181 & $469 \mathrm{bc}$ & 2184 a-e & 2434 a-d & $1719 \mathrm{~b}$ & 2112 \\
\hline 8 & OPATA//HAHN*2/PRL/3/IAC-24 & 1635 & 1392 & 1462 & 1497 a & 1496 e & 1927 cd & $2108 \mathrm{~b}$ & 1844 \\
\hline 9 & OPATA//HAHN*2/PRL/3/IAC-24 & 792 & 108 & 97 & $332 \mathrm{c}$ & 2187 a-d & 3253 a & $2931 \mathrm{ab}$ & 2790 \\
\hline 10 & OPATA//HAHN*2/PRL/3/IAC-24 & 563 & 424 & 201 & 396 c & $2535 \mathrm{ab}$ & $2979 \mathrm{ab}$ & $2139 \mathrm{~b}$ & 2551 \\
\hline 11 & OPATA / /HAHN*2/PRL/3/IAC-24 & 566 & 406 & 177 & $383 \mathrm{c}$ & 2816 a & 2809 a-d & $2059 \mathrm{~b}$ & 2561 \\
\hline 12 & OPATA / /HAHN*2/PRL/3/IAC-24 & 684 & 552 & 132 & $456 \mathrm{bc}$ & $2601 \mathrm{ab}$ & $2976 \mathrm{ab}$ & $2128 \mathrm{~b}$ & 2568 \\
\hline 13 & OPATA//HAHN*2/PRL/3/IAC-24 & 632 & 542 & 167 & $447 \mathrm{bc}$ & 2518 a-c & 3188 a & $2361 \mathrm{~b}$ & 2689 \\
\hline 14 & R27/GHL121//KAL/BB/3/BUC/BUL/4/IAC-24 & 1701 & 1337 & 1576 & 1538 a & 2396 a-c & $2344 \mathrm{a}-\mathrm{d}$ & $2215 b$ & 2318 \\
\hline 15 & R27/GHL121//KAL/BB/3/BUC/BUL/4/IAC-24 & 1611 & 1090 & 1295 & 1332 a & $2566 \mathrm{ab}$ & 2490 a-d & $2000 \mathrm{~b}$ & 2352 \\
\hline 16 & R27/GHL121 / / KAL/BB/3/BUC/BUL/4/IAC-24 & 1479 & 1556 & 1271 & 1435 a & $2524 \mathrm{a}-\mathrm{c}$ & $2365 \mathrm{a}-\mathrm{d}$ & $2590 \mathrm{~b}$ & 2493 \\
\hline 17 & R27/GHL121//KAL/BB/3/BUC/BUL/4/IAC-24 & 1753 & 1493 & 1069 & 1439 a & 2458 a-c & 2344 a-d & $2701 \mathrm{ab}$ & 2501 \\
\hline 18 & R27/GHL121 / / KAL/BB/3/BUC/BUL/4/IAC-24 & 1948 & 1330 & 1483 & 1587 a & 2316 a-c & 2510 a-d & $2590 \mathrm{~b}$ & 2472 \\
\hline 19 & MN 91309/IAC 24 & 1997 & 1493 & 1392 & 1627 a & 2114 b-e & $2101 \mathrm{~b}-\mathrm{d}$ & $2837 \mathrm{ab}$ & 2351 \\
\hline 20 & MN 91309/IAC 24 & 1597 & 1219 & 1368 & 1395 a & 1566 de & $1854 \mathrm{~d}$ & $2115 \mathrm{~b}$ & 1845 \\
\hline \multicolumn{2}{|c|}{ F (Repetições) } & $5,52^{*}$ & 0,95 & 1,94 & - & 1,87 & 0,50 & 1,98 & - \\
\hline \multicolumn{2}{|c|}{ F (Genótipos) } & $5,70^{*}$ & $11,18^{*}$ & $15,88^{*}$ & $18,86^{*}$ & $6,76^{*}$ & $3,76^{*}$ & $3,57^{*}$ & $2,13^{*}$ \\
\hline \multicolumn{2}{|l|}{ F (Anos) } & - & - & - & $21,77^{*}$ & - & - & - & $3,37^{*}$ \\
\hline \multicolumn{2}{|l|}{$\mathrm{F}(\mathrm{G} \times \mathrm{A})$} & - & - & - & 1,22 & - & - & - & $2,90^{*}$ \\
\hline \multicolumn{2}{|c|}{ d.m.s. (Tukey 5\%) } & 1132 & 766 & 792 & 632 & 690 & 1035 & 1320 & 1068 \\
\hline \multicolumn{2}{|l|}{ C.V. \% } & 32,71 & 28,06 & 33,50 & 33,95 & 11,51 & 15,36 & 20,78 & 16,65 \\
\hline
\end{tabular}

* Significativo ao nível de $5 \%$. 
Tabela 2. Testes de médias e análises da variância individuais e conjuntas (anos) para a variável altura das plantas, em centímetros, dos 20 genótipos de trigo avaliados nos Ensaios de Linhagens Provenientes de Cultura de Anteras, instalados em Capão Bonito e Tatuí em 2001,2002 e 2003

\begin{tabular}{|c|c|c|c|c|c|c|c|c|c|}
\hline \multirow{2}{*}{ Genótipos } & \multirow{2}{*}{ Genealogia } & \multicolumn{3}{|c|}{ Capão Bonito } & \multicolumn{5}{|c|}{ Tatuí } \\
\hline & & 2001 & 2002 & 2003 & Média & 2001 & 2002 & 2003 & Média \\
\hline & & \multicolumn{8}{|c|}{$\longrightarrow \mathrm{cm}-$} \\
\hline 1 & IAC-24 & $74 \mathrm{a}-\mathrm{c}$ & $69 \mathrm{a}-\mathrm{f}$ & $66 \mathrm{~b}-\mathrm{e}$ & 70 & $71 \mathrm{~cd}$ & $76 \mathrm{e}$ & 75 a-c & 74 \\
\hline 2 & IAC-370 & $73 \mathrm{a}-\mathrm{d}$ & $60 \mathrm{~b}-\mathrm{g}$ & 56 ef & 63 & $83 \mathrm{ab}$ & $90 \mathrm{ab}$ & $80 \mathrm{ab}$ & 84 \\
\hline 3 & $\begin{array}{l}\text { CEP83121/CEP83140/3/TJB88.1089/ALDAN/ } \\
\text { /CEP13/4/IAC-24 }\end{array}$ & $69 \mathrm{a}-\mathrm{f}$ & $69 \mathrm{a}-\mathrm{f}$ & $66 \mathrm{~b}-\mathrm{e}$ & 68 & $78 \mathrm{~b}-\mathrm{d}$ & 78 de & 76 a-c & 7 \\
\hline 4 & R27/GHL121//KAL/BB/3/BUC/BUL/4/IAC-24 & $76 \mathrm{ab}$ & 79 a-c & $80 \mathrm{a}-\mathrm{c}$ & 78 & $80 \mathrm{a}-\mathrm{d}$ & $85 \mathrm{~b}-\mathrm{e}$ & $80 \mathrm{ab}$ & 82 \\
\hline 5 & MAITEN / / BJY “S” /JUP /3/IAC-24 & $78 \mathrm{ab}$ & 70 a-e & $91 \mathrm{a}$ & 80 & 89 a & 96 a & 83 a & 89 \\
\hline 6 & GAA “S" / KAUZ "S" / / IAC-24 & $60 \mathrm{c}-\mathrm{g}$ & $49 \mathrm{e}-\mathrm{h}$ & $41 \mathrm{fg}$ & 50 & $73 \mathrm{~b}-\mathrm{d}$ & $81 \mathrm{~b}-\mathrm{e}$ & 73 a-c & 75 \\
\hline 7 & GAA “S" / KAUZ "S" / /IAC-24 & $64 \mathrm{~b}-\mathrm{g}$ & $59 \mathrm{c}-\mathrm{g}$ & 49 e-g & 57 & $78 \mathrm{~b}-\mathrm{d}$ & $76 \mathrm{e}$ & $69 \mathrm{bc}$ & 74 \\
\hline 8 & OPATA//HAHN*2/PRL/3/IAC-24 & 70 a-e & $60 \mathrm{~b}-\mathrm{g}$ & $65 \mathrm{c}-\mathrm{e}$ & 65 & $76 \mathrm{~b}-\mathrm{d}$ & $81 \mathrm{~b}-\mathrm{e}$ & $68 \mathrm{bc}$ & 75 \\
\hline 9 & OPATA//HAHN*2/PRL/3/IAC-24 & $51 \mathrm{~g}$ & $31 \mathrm{~h}$ & $35 \mathrm{~g}$ & 39 & $70 \mathrm{~d}$ & 79 c-e & $71 \mathrm{a}-\mathrm{c}$ & 73 \\
\hline 10 & OPATA//HAHN*2/PRL/3/IAC-24 & $53 \mathrm{~g}$ & $46 \mathrm{f}-\mathrm{h}$ & $40 \mathrm{fg}$ & 46 & $76 \mathrm{~b}-\mathrm{d}$ & 85 b-e & $68 \mathrm{bc}$ & 76 \\
\hline 11 & OPATA / /HAHN*2/PRL/3/IAC-24 & 58 e-g & 50 e-h & $43 \mathrm{fg}$ & 50 & $75 \mathrm{~b}-\mathrm{d}$ & $83 \mathrm{~b}-\mathrm{e}$ & $64 c$ & 74 \\
\hline 12 & OPATA/ /HAHN*2/PRL/3/IAC-24 & $59 \mathrm{~d}-\mathrm{g}$ & $51 \mathrm{~d}-\mathrm{h}$ & $41 \mathrm{fg}$ & 50 & 80 a-d & 85 b-e & 70 a-c & 78 \\
\hline 13 & OPATA//HAHN*2/PRL/3/IAC-24 & $55 \mathrm{fg}$ & $41 \mathrm{gh}$ & $40 \mathrm{fg}$ & 45 & $72 \mathrm{~cd}$ & $86 \mathrm{~b}-\mathrm{d}$ & $70 \mathrm{a}-\mathrm{c}$ & 76 \\
\hline 14 & R27/GHL121//KAL/BB/3/BUC/BUL/4/IAC-24 & $79 \mathrm{a}$ & $74 \mathrm{a}-\mathrm{d}$ & $85 \mathrm{ab}$ & 79 & $83 \mathrm{ab}$ & $85 \mathrm{~b}-\mathrm{e}$ & $78 \mathrm{ab}$ & 82 \\
\hline 15 & R27/GHL121//KAL/BB/3/BUC/BUL/4/IAC-24 & $81 \mathrm{a}$ & $78 \mathrm{a}-\mathrm{c}$ & $78 \mathrm{a}-\mathrm{d}$ & 79 & $81 \mathrm{a}-\mathrm{c}$ & $88 \mathrm{a}-\mathrm{c}$ & 76 a-c & 82 \\
\hline 16 & R27/GHL121 / / KAL/BB/3/BUC/BUL/4/IAC-24 & 79 a & 84 a & $79 \mathrm{a}-\mathrm{c}$ & 80 & $81 \mathrm{a}-\mathrm{c}$ & $85 \mathrm{~b}-\mathrm{e}$ & 83 a & 83 \\
\hline 17 & R27/GHL121//KAL/BB/3/BUC/BUL/4/IAC-24 & $76 \mathrm{ab}$ & $84 \mathrm{a}$ & $78 \mathrm{a}-\mathrm{d}$ & 79 & $78 \mathrm{~b}-\mathrm{d}$ & 85 b-e & $80 \mathrm{ab}$ & 81 \\
\hline 18 & R27/GHL121//KAL/BB/3/BUC/BUL/4/IAC-24 & $79 \mathrm{a}$ & $83 \mathrm{ab}$ & $84 \mathrm{a}-\mathrm{c}$ & 82 & 79 a-d & $86 \mathrm{~b}-\mathrm{d}$ & $78 \mathrm{ab}$ & 81 \\
\hline 19 & MN 91309/IAC 24 & $73 \mathrm{a}-\mathrm{d}$ & $78 \mathrm{a}-\mathrm{c}$ & $78 \mathrm{a}-\mathrm{d}$ & 76 & 79 a-d & $87 \mathrm{a}-\mathrm{d}$ & $81 \mathrm{ab}$ & 82 \\
\hline 20 & MN 91309/IAC 24 & $76 \mathrm{ab}$ & 76 a-c & $76 \mathrm{a}-\mathrm{d}$ & 76 & $71 \mathrm{~cd}$ & 85 b-e & 73 a-c & 76 \\
\hline \multicolumn{2}{|c|}{ F (Repetições) } & $16,94^{*}$ & 0,66 & 1,41 & - & 1,49 & $12,22^{*}$ & 0,75 & - \\
\hline \multicolumn{2}{|c|}{ F (Genótipos) } & $13,71^{*}$ & $11,93^{*}$ & $23,47^{*}$ & $12,28^{*}$ & $4,54^{*}$ & $5,65^{*}$ & 4,19 & $5,18^{*}$ \\
\hline \multicolumn{2}{|c|}{ F (Anos) } & - & - & - & $5,15^{*}$ & - & - & - & $44,65^{*}$ \\
\hline \multicolumn{2}{|l|}{$\mathrm{F}(\mathrm{G} \times \mathrm{A})$} & - & - & - & $2,12^{*}$ & - & - & - & $1,71^{*}$ \\
\hline \multicolumn{2}{|c|}{ d.m.s. (Tukey 5\%) } & 14 & 24 & 20 & 18 & 11 & 10 & 14 & 10 \\
\hline \multicolumn{2}{|c|}{ C.V. \% } & 7,71 & 13,95 & 12,05 & 12,13 & 5,65 & 4,70 & 7,31 & 6,28 \\
\hline
\end{tabular}

* Significativo ao nível de $5 \%$. 
Tabela 3. Testes de médias e análises da variância individuais e conjuntas (anos) para as variáveis ciclo da emergência ao florescimento e da emergência à maturação, em dias, dos 20 genótipos de trigo avaliados nos Ensaios de Linhagens Provenientes de Cultura de Anteras, instalados em Capão Bonito em 2001, 2002 e 2003

\begin{tabular}{|c|c|c|c|c|c|c|c|c|c|}
\hline \multirow{2}{*}{ Genótipos } & \multirow{2}{*}{ Genealogia } & \multicolumn{4}{|c|}{ Emergência - florescimento } & \multicolumn{3}{|c|}{ Emergência - maturação } & \multirow[b]{2}{*}{ Média } \\
\hline & & 2001 & 2002 & 2003 & Média & 2001 & 2002 & 2003 & \\
\hline & & \multicolumn{8}{|c|}{${ }^{2}$ dias -} \\
\hline 1 & IAC-24 & $77 \mathrm{c}$ & $67 \mathrm{bc}$ & $75 \mathrm{a}-\mathrm{c}$ & 73 & $140 \mathrm{~b}$ & $132 \mathrm{ab}$ & $142 \mathrm{a}-\mathrm{c}$ & 138 \\
\hline 2 & IAC-370 & $77 \mathrm{c}$ & $69 \mathrm{ab}$ & $68 \mathrm{c}$ & 71 & $140 \mathrm{~b}$ & $132 \mathrm{ab}$ & 137 a-d & 136 \\
\hline 3 & $\begin{array}{l}\text { CEP83121/CEP83140/3/TJB88.1089/ALDAN/ } \\
\text { /CEP13/4/IAC-24 }\end{array}$ & $77 \mathrm{c}$ & $61 c$ & $68 c$ & 69 & $140 \mathrm{~b}$ & $120 \mathrm{bc}$ & $123 \mathrm{~d}$ & 128 \\
\hline 4 & R27/GHL121 / /KAL/BB/3/BUC/BUL/4/IAC-24 & $89 \mathrm{ab}$ & $75 \mathrm{a}$ & $84 \mathrm{a}$ & 83 & $145 \mathrm{ab}$ & 138 a & 148 a & 144 \\
\hline 5 & MAITEN/ / BJY “S” /JUP/3/IAC-24 & $77 \mathrm{c}$ & $61 \mathrm{c}$ & $68 c$ & 69 & $140 \mathrm{~b}$ & 126 a-c & $127 \mathrm{~cd}$ & 131 \\
\hline 6 & GAA "S" / KAUZ "S" / /IAC-24 & $80 \mathrm{bc}$ & $63 \mathrm{bc}$ & $71 \mathrm{bc}$ & 71 & $140 \mathrm{~b}$ & $116 \mathrm{c}$ & 135 a-d & 130 \\
\hline 7 & GAA “S” / KAUZ “S" / / IAC-24 & $77 \mathrm{c}$ & $61 \mathrm{c}$ & $72 \mathrm{bc}$ & 70 & $140 \mathrm{~b}$ & $114 \mathrm{c}$ & 133 a-d & 129 \\
\hline 8 & OPATA / /HAHN*2/PRL/3/IAC-24 & $77 \mathrm{c}$ & $66 \mathrm{bc}$ & $71 \mathrm{bc}$ & 71 & $140 \mathrm{~b}$ & 126 a-c & $128 \mathrm{~cd}$ & 131 \\
\hline 9 & OPATA//HAHN*2/PRL/3/IAC-24 & $83 \mathrm{a}-\mathrm{c}$ & $67 \mathrm{bc}$ & $75 \mathrm{a}-\mathrm{c}$ & 75 & $140 \mathrm{~b}$ & $114 \mathrm{c}$ & $130 \mathrm{~b}-\mathrm{d}$ & 128 \\
\hline 10 & OPATA//HAHN*2/PRL/3/IAC-24 & $81 \mathrm{a}-\mathrm{c}$ & $70 \mathrm{ab}$ & $72 \mathrm{bc}$ & 74 & $140 \mathrm{~b}$ & $116 \mathrm{c}$ & $131 \mathrm{~b}-\mathrm{d}$ & 129 \\
\hline 11 & OPATA//HAHN*2/PRL/3/IAC-24 & $80 \mathrm{bc}$ & $66 \mathrm{bc}$ & 75 a-c & 73 & $140 \mathrm{~b}$ & 117 c & $130 \mathrm{~b}-\mathrm{d}$ & 129 \\
\hline 12 & OPATA / /HAHN*2/PRL/3/IAC-24 & $81 \mathrm{a}-\mathrm{c}$ & $63 \mathrm{bc}$ & 76 a-c & 73 & $140 \mathrm{~b}$ & $116 \mathrm{c}$ & $133 \mathrm{a}-\mathrm{d}$ & 129 \\
\hline 13 & OPATA//HAHN*2/PRL/3/IAC-24 & $81 \mathrm{a}-\mathrm{c}$ & $63 \mathrm{bc}$ & $72 \mathrm{bc}$ & 72 & $140 \mathrm{~b}$ & $116 \mathrm{c}$ & $129 \mathrm{~b}-\mathrm{d}$ & 128 \\
\hline 14 & R27/GHL121 / /KAL/BB /3 / BUC /BUL/4/IAC-24 & $89 \mathrm{ab}$ & 75 a & $84 \mathrm{a}$ & 83 & 147 a & 138 a & 148 a & 144 \\
\hline 15 & R27/GHL121 / / KAL/BB/3/BUC/BUL/4/IAC-24 & $89 \mathrm{ab}$ & 75 a & $84 \mathrm{a}$ & 83 & 147 a & 138 a & 148 a & 144 \\
\hline 16 & R27/GHL121 / /KAL/BB/3/BUC/BUL/4/IAC-24 & $89 \mathrm{ab}$ & $75 \mathrm{a}$ & $84 \mathrm{a}$ & 83 & 149 a & 138 a & $144 \mathrm{ab}$ & 144 \\
\hline 17 & R27/GHL121 / /KAL/BB/3/BUC/BUL/4/IAC-24 & $87 \mathrm{ab}$ & $75 \mathrm{a}$ & $84 \mathrm{a}$ & 82 & 149 a & 138 a & 148 a & 145 \\
\hline 18 & R27/GHL121 / / KAL/BB/3 / BUC /BUL/4/IAC-24 & 90 a & 75 a & $84 \mathrm{a}$ & 83 & 147 a & 138 a & 148 a & 144 \\
\hline 19 & MN 91309/IAC 24 & $80 \mathrm{bc}$ & $75 \mathrm{a}$ & 83 a & 79 & $140 \mathrm{~b}$ & 135 a & $140 \mathrm{a}-\mathrm{c}$ & 138 \\
\hline 20 & MN 91309/IAC 24 & $77 \mathrm{c}$ & $61 \mathrm{c}$ & $80 \mathrm{ab}$ & 73 & $140 \mathrm{~b}$ & $132 \mathrm{ab}$ & $140 \mathrm{a}-\mathrm{c}$ & 137 \\
\hline \multicolumn{2}{|c|}{ F (Repetições) } & $2,87^{*}$ & 1,25 & 0,53 & - & 0,22 & 0,20 & 0,93 & - \\
\hline \multicolumn{2}{|c|}{ F (Genótipos) } & $6,06^{*}$ & $14,02^{*}$ & $9,94^{*}$ & $12,84^{*}$ & $10,49^{*}$ & $16,53^{*}$ & $7,06^{*}$ & $6,54^{*}$ \\
\hline \multicolumn{2}{|l|}{ F (Anos) } & - & - & - & $144,21^{*}$ & - & - & - & $57,21^{*}$ \\
\hline \multicolumn{2}{|c|}{$F(G \times A)$} & - & - & - & $1,85^{*}$ & - & - & - & $3,82^{*}$ \\
\hline \multicolumn{2}{|c|}{ d.m.s. (Tukey 5\%) } & 10 & 8 & 11 & 8 & 6 & 13 & 16 & 14 \\
\hline \multicolumn{2}{|l|}{ C.V. \% } & 4,88 & 4,54 & 5,25 & 5,01 & 1,50 & 3,86 & 4,54 & 3,46 \\
\hline
\end{tabular}

* Significativo ao nível de $5 \%$. 
Tabela 4. Plantas acamadas, em porcentagem, dos 20 genótipos de trigo avaliados nos Ensaios de Linhagens Provenientes de Cultura de Anteras, instalados em Capão Bonito e Tatuí em 2001, 2002 e 2003

\begin{tabular}{|c|c|c|c|c|c|c|c|c|c|}
\hline \multirow{2}{*}{ Genótipos } & \multirow{2}{*}{ Genealogia } & \multicolumn{3}{|c|}{ Capão Bonito } & \multicolumn{5}{|c|}{ Tatuí } \\
\hline & & 2001 & 2002 & 2003 & Média & 2001 & 2002 & 2003 & Média \\
\hline 1 & IAC-24 & 20 & 20 & 0 & 13 & 20 & 0 & 0 & 7 \\
\hline 2 & IAC-370 & 0 & 0 & 0 & 0 & 0 & 0 & 20 & 7 \\
\hline 3 & $\begin{array}{l}\text { CEP83121/CEP83140/3/TJB88.1089/ALDAN/ } \\
\text { /CEP13/4/IAC-24 }\end{array}$ & 40 & 20 & 0 & 20 & 20 & 20 & 20 & 20 \\
\hline 4 & R27/GHL121//KAL/BB/3/BUC/BUL/4/IAC-24 & 20 & 0 & 0 & 7 & 20 & 0 & 0 & 7 \\
\hline 5 & MAITEN//BJY “S”/JUP/3/IAC-24 & 60 & 20 & 0 & 27 & 20 & 20 & 20 & 20 \\
\hline 6 & GAA “S" / KAUZ "S" / / IAC-24 & 40 & 40 & 0 & 27 & 40 & 20 & 40 & 33 \\
\hline 7 & GAA "S" / KAUZ "S" / / IAC-24 & 40 & 20 & 0 & 20 & 20 & 20 & 20 & 20 \\
\hline 8 & OPATA//HAHN*2/PRL/3/IAC-24 & 20 & 20 & 0 & 13 & 0 & 0 & 0 & 0 \\
\hline 9 & OPATA//HAHN²/PRL/3/IAC-24 & 20 & 0 & 0 & 7 & 20 & 0 & 0 & 7 \\
\hline 10 & OPATA//HAHN*2/PRL/3/IAC-24 & 0 & 20 & 0 & 7 & 40 & 20 & 0 & 20 \\
\hline 11 & OPATA//HAHN*2/PRL/3/IAC-24 & 20 & 20 & 0 & 13 & 0 & 0 & 0 & 0 \\
\hline 12 & OPATA / /HAHN*2/PRL/3/IAC-24 & 20 & 0 & 0 & 7 & 0 & 0 & 0 & 0 \\
\hline 13 & OPATA/ /HAHN*2/PRL/3/IAC-24 & 40 & 0 & 0 & 13 & 0 & 0 & 0 & 0 \\
\hline 14 & R27/GHL121 / / KAL/BB /3 / BUC /BUL/4/IAC-24 & 0 & 20 & 0 & 7 & 0 & 0 & 0 & 0 \\
\hline 15 & R27/GHL121//KAL/BB/3/BUC/BUL/4/IAC-24 & 0 & 0 & 0 & 0 & 0 & 0 & 0 & 0 \\
\hline 16 & R27/GHL121 / / KAL/BB/3/BUC/BUL/4/IAC-24 & 0 & 0 & 0 & 0 & 0 & 0 & 0 & 0 \\
\hline 17 & R27 / GHL121 / / KAL/BB/3/BUC/BUL/4/IAC-24 & 0 & 0 & 0 & 0 & 20 & 0 & 0 & 7 \\
\hline 18 & R27/GHL121 / / KAL/BB /3 /BUC /BUL/4/IAC-24 & 20 & 0 & 0 & 7 & 0 & 0 & 0 & 0 \\
\hline 19 & MN 91309/IAC 24 & 20 & 0 & 0 & 7 & 0 & 0 & 0 & 0 \\
\hline 20 & MN 91309/IAC 24 & 20 & 0 & 0 & 7 & 20 & 0 & 0 & 7 \\
\hline
\end{tabular}


Tabela 5. Graus médios de infecção de mancha-da-folha $\left({ }^{1}\right)$ dos 20 genótipos de trigo avaliados nos Ensaios de Linhagens Provenientes de Cultura de Anteras, instalados em Capão Bonito e Tatuí em 2001, 2002 e 2003

\begin{tabular}{|c|c|c|c|c|c|c|}
\hline \multirow{2}{*}{ Genótipos } & \multirow{2}{*}{ Genealogia } & \multicolumn{3}{|c|}{ Capão Bonito } & \multicolumn{2}{|r|}{ Tatuí } \\
\hline & & 2001 & 2002 & 2003 & Média & 2001 \\
\hline & & & & $-\%$ & & 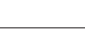 \\
\hline 1 & IAC-24 & 50 & 10 & 50 & 37 & 30 \\
\hline 2 & IAC-370 & 30 & 20 & 40 & 30 & 30 \\
\hline 3 & $\begin{array}{l}\text { CEP83121/CEP83140/3/TJB88.1089/ALDAN/ } \\
\text { /CEP13/4/IAC-24 }\end{array}$ & 60 & 20 & 50 & 43 & 40 \\
\hline 4 & R27/GHL121 / /KAL/BB/3/BUC/BUL/4/IAC-24 & 30 & 10 & 40 & 27 & 20 \\
\hline 5 & MAITEN/ / BJY “S” /JUP/3/IAC-24 & 50 & 20 & 50 & 40 & 30 \\
\hline 6 & GAA "S" / KAUZ "S" / / IAC-24 & 60 & 20 & 60 & 47 & 30 \\
\hline 7 & GAA "S" / KAUZ "S" / / IAC-24 & 50 & 10 & 50 & 37 & 40 \\
\hline 8 & OPATA / /HAHN*2/PRL/3/IAC-24 & 50 & 20 & 60 & 43 & 50 \\
\hline 9 & OPATA / /HAHN*2/PRL/3/IAC-24 & 60 & 10 & 40 & 37 & 30 \\
\hline 10 & OPATA / /HAHN*2/PRL/3/IAC-24 & 40 & 20 & 40 & 33 & 40 \\
\hline 11 & OPATA / /HAHN*2/PRL/3/IAC-24 & 40 & 10 & 40 & 30 & 30 \\
\hline 12 & OPATA//HAHN*2/PRL/3/IAC-24 & 50 & 20 & 60 & 43 & 40 \\
\hline 13 & OPATA//HAHN*2/PRL/3/IAC-24 & 50 & 10 & 50 & 37 & 20 \\
\hline 14 & R27/GHL121 / / KAL/BB /3 /BUC /BUL/4/IAC-24 & 30 & 10 & 10 & 17 & 20 \\
\hline 15 & R27 / GHL121 / / KAL/BB/3 / BUC /BUL/4/IAC-24 & 30 & 10 & 20 & 20 & 40 \\
\hline 16 & R27/GHL121 / /KAL/BB/3/BUC/BUL/4/IAC-24 & 40 & 10 & 30 & 27 & 30 \\
\hline 17 & R27/GHL121 / / KAL/BB/3/BUC /BUL/4/IAC-24 & 40 & 10 & 30 & 27 & 20 \\
\hline 18 & R27/GHL121 / / KAL/BB/3/BUC /BUL/4/IAC-24 & 30 & 10 & 10 & 17 & 30 \\
\hline 19 & MN 91309/IAC 24 & 50 & 10 & 30 & 30 & 30 \\
\hline 20 & MN 91309/IAC 24 & 50 & 10 & 60 & 40 & 40 \\
\hline
\end{tabular}

$\left({ }^{1}\right)$ Avaliação de mancha-da-folha segundo Menta (1978): $0=$ imune; $1 \%$ a 5\% de área infectada $=$ resistente; $6 \%$ a $25 \%=$ moderadamente resistente; $26 \%$ a $50 \%=$ suscetível, e $51 \%$ a $99 \%$ = altamente suscetível. 
Tabela 6. Graus médios de infecção de ferrugem-da-folha $\left({ }^{1}\right)$ dos 20 genótipos de trigo avaliados nos Ensaios de Linhagens Provenientes de Cultura de Anteras, instalados em Capão Bonito e Tatuí em 2001, 2002 e 2003

\begin{tabular}{|c|c|c|c|c|c|c|}
\hline \multirow{2}{*}{ Genótipos } & \multirow{2}{*}{ Genealogia } & \multicolumn{3}{|c|}{ Capão Bonito } & \multicolumn{2}{|r|}{ Tatuí } \\
\hline & & 2001 & 2002 & 2003 & Média & 2002 \\
\hline & & & & $-\%-$ & & + \\
\hline 1 & IAC-24 & $5 S$ & $20 S$ & $20 S$ & $15 S$ & $20 \mathrm{~S}$ \\
\hline 2 & IAC-370 & $5 S$ & $10 \mathrm{~S}$ & $10 \mathrm{~S}$ & $8 \mathrm{~S}$ & $10 \mathrm{~S}$ \\
\hline 3 & $\begin{array}{l}\text { CEP83121/CEP83140/3/TJB88.1089/ALDAN/ } \\
\text { /CEP13/4/IAC-24 }\end{array}$ & tS & $10 \mathrm{~S}$ & $30 \mathrm{~S}$ & $14 \mathrm{~S}$ & $20 \mathrm{~S}$ \\
\hline 4 & R27/GHL121//KAL/BB/3/BUC/BUL/4/IAC-24 & 0 & 0 & tS & 0 & 0 \\
\hline 5 & MAITEN/ / BJY “S” /JUP/3/IAC-24 & tS & $20 S$ & $20 S$ & $14 \mathrm{~S}$ & $20 \mathrm{~S}$ \\
\hline 6 & GAA "S" / KAUZ "S" / /IAC-24 & $5 S$ & $5 S$ & $10 \mathrm{~S}$ & $7 S$ & $10 \mathrm{~S}$ \\
\hline 7 & GAA “S" / KAUZ "S" / / IAC-24 & $10 \mathrm{~S}$ & $5 S$ & $5 S$ & $7 S$ & $10 \mathrm{~S}$ \\
\hline 8 & OPATA//HAHN*2/PRL/3/IAC-24 & $5 S$ & $10 \mathrm{~S}$ & $20 S$ & $12 S$ & $5 S$ \\
\hline 9 & OPATA//HAHN*2/PRL/3/IAC-24 & $\mathrm{tS}$ & $5 S$ & 0 & $2 S$ & $10 \mathrm{~S}$ \\
\hline 10 & OPATA//HAHN*2/PRL/3/IAC-24 & tS & $10 \mathrm{~S}$ & 0 & $4 S$ & $5 S$ \\
\hline 11 & OPATA//HAHN*2/PRL/3/IAC-24 & $10 \mathrm{~S}$ & $5 S$ & 0 & $5 S$ & $5 S$ \\
\hline 12 & OPATA//HAHN*2/PRL/3/IAC-24 & $5 S$ & $20 \mathrm{~S}$ & 0 & $8 \mathrm{~S}$ & $5 S$ \\
\hline 13 & OPATA//HAHN*2/PRL/3/IAC-24 & tS & $\mathrm{tS}$ & $10 \mathrm{~S}$ & $4 S$ & $20 \mathrm{~S}$ \\
\hline 14 & R27/GHL121//KAL/BB/3/BUC/BUL/4/IAC-24 & 0 & tS & 0 & 0 & 0 \\
\hline 15 & R27/GHL121//KAL/BB/3/BUC/BUL/4/IAC-24 & 0 & 0 & 0 & 0 & 0 \\
\hline 16 & R27/GHL121//KAL/BB/3/BUC/BUL/4/IAC-24 & 0 & 0 & 0 & 0 & 0 \\
\hline 17 & R27/GHL121//KAL/BB/3/BUC/BUL/4/IAC-24 & 0 & 0 & 0 & 0 & 0 \\
\hline 18 & R27/GHL121//KAL/BB/3/BUC/BUL/4/IAC-24 & 0 & 0 & tS & 0 & 0 \\
\hline 19 & MN 91309/IAC 24 & $5 S$ & $20 \mathrm{~S}$ & $10 \mathrm{~S}$ & $12 S$ & $5 S$ \\
\hline 20 & MN 91309/IAC 24 & $10 \mathrm{~S}$ & $20 \mathrm{~S}$ & $10 \mathrm{~S}$ & $13 S$ & $5 S$ \\
\hline
\end{tabular}

$\left({ }^{1}\right) \mathrm{t}=$ traço (apenas algumas pústulas); $\mathrm{S}=$ reação de suscetibilidade. Avaliação de ferrugem-da-folha foi feita segundo ScHRAmm et. al. (1974). 
Os quadrados médios das análises da variância para comprimento da espiga, número de espiguetas por espiga, número de grãos por espiga e por espigueta e massa de cem grãos do experimento de Tatuí (2002) foram significativos para genótipos e não significativos para repetições, com exceção do número de espiguetas por espiga (Tabela 7).

Na cultivar IAC-370 observaram-se as espigas mais compridas e o maior número de grãos por espiga, diferindo, das linhagens L5, L9, L10, L11 e L13, e da cultivar IAC-24, com as mais curtas. Também diferiu das linhagens diaplóides L3, L6 e L7, quanto ao número de grãos por espiga. Na cultivar IAC-370 e na linhagem L5 verificou-se o maior número de grãos por espigueta (maior fertilidade da espiga), diferindo apenas de L6 e L7 com espigas de baixa fertilidade. A cultivar IAC370 tem potencial para ser utilizada como fonte genética dessas características no programa de cruzamentos do Instituto Agronômico, pelas espigas compridas e maior número de grãos por espiga e por espigueta.

$\mathrm{Na}$ linhagem L8 notou-se o maior valor em relação ao número de espiguetas por espiga, mas diferindo, apenas, de L3, L5, L6, L7 e L17. As linhagens L6 e L7 revelaram os grãos mais pesados, não diferindo, somente, das linhagens L3 e L5. Foram também identificados genótipos mexicanos portadores de espigas compridas, com maior número de espiguetas por espiga, de grãos por espiga e por espigueta e com maior massa de cem grãos que poderão ser utilizados em cruzamentos como fontes genéticas dessas características (Lobato et al., 2005).

$\mathrm{Na}$ tabela 8 observa-se o comprimento médio das raízes dos 20 genótipos de trigo avaliados, além das cultivares-controle BH-1146 (tolerante) e Anahuac (sensível), referente a média de duas repetições.

A cultivar-controle Anahuac e as linhagens L9, L11, L12 e L13 foram sensíveis à concentração de 2 $\mathrm{mg} \mathrm{L}^{-1}$ de $\mathrm{Al}^{3+}$ (Tabela 8), ou seja, houve paralisação irreversível do crescimento da raiz primária central, após, esse tratamento. Todos os demais genótipos foram tolerantes, isto é, exibiram algum crescimento radicular após tratamento em solução contendo essa concentração de alumínio. L10 foi considerada sensível às concentrações a partir de $4 \mathrm{mg} \mathrm{L}^{-1}$ de $\mathrm{Al}^{3+}$; a cultivar IAC-370 e as linhagens L6 e L7 foram sensíveis às concentrações a partir de $6 \mathrm{mg} \mathrm{L}^{-1}$ de $\mathrm{Al}^{3+}$. Os demais genótipos foram tolerantes às concentrações de 8 e $10 \mathrm{mg} \mathrm{L}^{-1}$ de $\mathrm{Al}^{3+}$, com exceção da L8, que foi sensível a $10 \mathrm{mg} \mathrm{L}^{-1}$ de $\mathrm{Al}^{3+}$.
A alta tolerância da cultivar IAC-24 e a sensibilidade da 'Anahuac' observadas neste trabalho estão de acordo com os resultados de Tulmann et al. (2002), quando essas cultivares tiveram, respectivamente, altas e baixas produções médias de grãos, nos experimentos instalados em solo ácido de Capão Bonito, no período 1994-1996.

Em relação à toxicidade de alumínio as linhagens diaplóides (L4, L14, L15, L16, L17 e L18) oriundas do cruzamento entre a cultivar IAC-24 e a linhagem mexicana R27/GHL121//KAL/BB/3/ BUC/BUL, foram tolerantes. Pela tolerância verificada, herdada desses genitores, sugere-se que eles possam servir como fonte de tolerância à toxicidade de $\mathrm{Al}^{3+}$ em programa de melhoramento visando a essa característica.

Considerando-se os experimentos de Capão Bonito (2001-03), relatados no presente trabalho, as correlações simples foram positivas e significativas entre as produções médias de grãos de cada genótipo e os respectivos comprimentos médios das raízes, medido após 72 horas de crescimento na solução nutritiva, que se seguiu ao crescimento na soluçãotratamento contendo $2\left(0,95^{*}\right), 4\left(0,93^{*}\right), 6\left(0,91^{*}\right), 8$ $\left(0,91^{*}\right)$ e $10\left(0,66^{*}\right) \mathrm{mg} \cdot \mathrm{L}^{-1}$ de $\mathrm{Al}^{3+}$. Levando-se em conta os experimentos de Tatuí (2001-2003), as correlações simples calculadas foram não significativas entre as médias de produções de grãos de cada genótipo e o comprimento médio das raízes, em cada concentração de alumínio.

Esses resultados poderiam ser explicados considerando-se que nos experimentos de Capão Bonito, em condição de sequeiro e solo ácido sem aplicação de calcário, a presença de alumínio na camada arável prejudicou o desenvolvimento dos genótipos mais sensíveis à toxicidade de alumínio, confirmando os resultados obtidos com as soluções nutritivas.

Nos experimentos instalados em Tatuí, em solo ácido com aplicação de calcário e com irrigação por aspersão, as raízes dos genótipos foram mantidas em quase sua totalidade na camada arável.

Esse fato impediu que a provável presença de alumínio no subsolo representasse um fator de limitação para o desenvolvimento dos genótipos avaliados. Nesse caso, os resultados conseguidos com o uso de soluções nutritivas não puderam ser confirmados. Esses resultados concordam com os relatados por SALOMON et al., 2003, nos quais os genótipos mais produtivos em solo ácido estavam associados com a tolerância à toxicidade de $\mathrm{Al}^{3+}$, em soluções nutritivas. 
Tabela 7. Testes de médias e análises da variância individuais para as variáveis comprimento das espigas (cm), espiguetas por espiga (nº), grãos por espiga e por espigueta $\left(\mathrm{n}^{\circ}{ }^{\circ}\right)$, e massa de cem grãos $\left({ }^{\mathrm{g}}\right)$, dos 20 genótipos de trigo avaliados nos Ensaios de Linhagens Provenientes de Cultura de Anteras, instalado em Tatuí, em 2002

\begin{tabular}{|c|c|c|c|c|c|c|}
\hline \multirow[t]{2}{*}{ Genótipos } & \multirow[t]{2}{*}{ Genealogia } & \multirow{2}{*}{$\begin{array}{c}\text { Comprimento } \\
\text { das espigas }\end{array}$} & $\begin{array}{l}\text { Espiguetas por } \\
\text { espiga }\end{array}$ & \multirow[t]{2}{*}{$\begin{array}{l}\text { Grãos por } \\
\text { espiga }\end{array}$} & \multirow{2}{*}{$\begin{array}{l}\text { Grãos por } \\
\text { espigueta }\end{array}$} & \multirow{2}{*}{$\begin{array}{c}\begin{array}{c}\text { Massa de } \\
\text { cem grãos }\end{array} \\
\mathrm{g}\end{array}$} \\
\hline & & & $\mathrm{n}^{\mathrm{o}}$ & & & \\
\hline 1 & IAC-24 & 9,1 b-e & 19,9 a-d & $45,0 \mathrm{ab}$ & $2,28 \mathrm{ab}$ & $3,58 \mathrm{~b}-\mathrm{d}$ \\
\hline 2 & IAC-370 & 11,1 a & 19,7 a-d & 46,9 a & 2,38 a & $3,57 \mathrm{~b}-\mathrm{e}$ \\
\hline 3 & $\begin{array}{l}\text { CEP83121/CEP83140/3/TJB88.1089/ALDAN/ } \\
\text { /CEP13/4/IAC-24 }\end{array}$ & 9,7 a-e & $17,5 \mathrm{~d}$ & $33,4 \mathrm{~b}-\mathrm{d}$ & $1,91 \mathrm{a}-\mathrm{c}$ & $4,08 \mathrm{ab}$ \\
\hline 4 & R27 / GHL121 / / KAL / BB /3 / BUC / BUL/4 /IAC-24 & 10,3 a-e & 19,7 a-d & 40,0 a-c & $2,03 \mathrm{a}-\mathrm{c}$ & $2,52 \mathrm{gh}$ \\
\hline 5 & MAITEN/ / BJY “S” /JUP/3/IAC-24 & $8,5 \mathrm{e}$ & $17,8 \mathrm{~cd}$ & 42,6 a-c & $2,41 \mathrm{a}$ & $3,99 \mathrm{a}-\mathrm{c}$ \\
\hline 6 & GAA “S" / KAUZ "S" / / IAC-24 & 10,1 a-e & $18,4 \mathrm{~b}-\mathrm{d}$ & $31,0 \mathrm{~cd}$ & $1,69 \mathrm{bc}$ & 4,43 a \\
\hline 7 & GAA “S" / KAUZ "S" / / IAC-24 & 10,0 a-e & $18,2 \mathrm{~b}-\mathrm{d}$ & $27,2 \mathrm{~d}$ & $1,51 \mathrm{c}$ & $4,51 \mathrm{a}$ \\
\hline 8 & OPATA//HAHN*2/PRL/3/IAC-24 & 9,4 a-e & $21,7 \mathrm{a}$ & $41,7 \mathrm{a}-\mathrm{c}$ & $1,91 \mathrm{a}-\mathrm{c}$ & $2,76 \mathrm{~d}-\mathrm{h}$ \\
\hline 9 & OPATA//HAHN*2/PRL/3/IAC-24 & 8,6 de & 19,7 a-d & 41,0 a-c & $2,09 a-c$ & $2,90 \mathrm{~d}-\mathrm{h}$ \\
\hline 10 & OPATA//HAHN*2/PRL/3/IAC-24 & 9,1 b-e & 19,8 a-d & $44,4 \mathrm{ab}$ & $2,24 \mathrm{ab}$ & 2,75 e-h \\
\hline 11 & OPATA / /HAHN*2/PRL/3/IAC-24 & 9,0 c-e & 19,6 a-d & 42,6 a-c & $2,20 \mathrm{ab}$ & $2,76 \mathrm{~d}-\mathrm{h}$ \\
\hline 12 & OPATA//HAHN*2/PRL/3/IAC-24 & 9,5 a-e & $20,2 \mathrm{a}-\mathrm{c}$ & $43,7 \mathrm{ab}$ & $2,17 \mathrm{ab}$ & $2,82 \mathrm{~d}-\mathrm{h}$ \\
\hline 13 & OPATA//HAHN*2/PRL/3/IAC-24 & 8,6 de & 19,6 a-d & 41,4 a-c & $2,12 \mathrm{ab}$ & $3,23 \mathrm{c}-\mathrm{g}$ \\
\hline 14 & R27/GHL121 / / KAL/BB/3/BUC/BUL/4/IAC-24 & 10,4 a-d & 19,6 a-d & 39,3 a-d & $2,02 \mathrm{a}-\mathrm{c}$ & $2,66 \mathrm{f}-\mathrm{h}$ \\
\hline 15 & R27/GHL121 / / KAL/BB/3/BUC/BUL/4/IAC-24 & $10,7 \mathrm{a}-\mathrm{c}$ & $20,2 \mathrm{a}-\mathrm{c}$ & $42,7 \mathrm{a}-\mathrm{c}$ & $2,10 \mathrm{a}-\mathrm{c}$ & $2,43 \mathrm{gh}$ \\
\hline 16 & R27/GHL121 / / KAL/BB/3/BUC /BUL/4/IAC-24 & 9,8 a-e & $20,0 \mathrm{a}-\mathrm{c}$ & 39,6 a-c & $1,97 \mathrm{a}-\mathrm{c}$ & $2,33 \mathrm{~h}$ \\
\hline 17 & R27/GHL121 / / KAL/BB/3/BUC /BUL/4/IAC-24 & 10,6 a-c & $19,2 \mathrm{~b}-\mathrm{d}$ & 38,4 a-d & $2,00 \mathrm{a}-\mathrm{c}$ & $2,64 \mathrm{f}-\mathrm{h}$ \\
\hline 18 & R27/GHL121 / / KAL/BB/3 /BUC /BUL/4/IAC-24 & $10,9 \mathrm{ab}$ & $20,1 \mathrm{a}-\mathrm{c}$ & $41,3 \mathrm{a}-\mathrm{c}$ & $2,04 \mathrm{a}-\mathrm{c}$ & $2,54 \mathrm{gh}$ \\
\hline 19 & MN 91309/IAC 24 & $10,9 \mathrm{ab}$ & $20,6 \mathrm{ab}$ & $42,5 \mathrm{a}-\mathrm{c}$ & $2,06 \mathrm{a}-\mathrm{c}$ & $2,98 \mathrm{~d}-\mathrm{h}$ \\
\hline 20 & MN 91309/IAC 24 & 10,6 a-c & 19,7 a-d & 36,2 a-d & $1,85 \mathrm{a}-\mathrm{c}$ & $3,40 \mathrm{~b}-\mathrm{f}$ \\
\hline \multicolumn{2}{|c|}{ F (Repetições) } & 0,90 & $4,07^{*}$ & 1,21 & 0,56 & 2,62 \\
\hline \multicolumn{2}{|c|}{ F (Genótipos) } & $5,39 *$ & $4,25^{*}$ & $4,20 *$ & $3,51^{*}$ & $17,99 *$ \\
\hline \multicolumn{2}{|c|}{ d.m.s. (Tukey 5\%) } & 1,9 & 2,5 & 12,4 & 0,61 & 0,83 \\
\hline \multicolumn{2}{|l|}{ C.V. \% } & 7,28 & 4,84 & 11,84 & 11,26 & 10,11 \\
\hline
\end{tabular}

* Significativo ao nível de $5 \%$. 
Tabela 8. Comprimento médio ( $\mathrm{mm}$ ) das raízes dos 20 genótipos de trigo avaliados nos Ensaios de Linhagens Provenientes de Cultura de Anteras, após 72 horas de crescimento em solução normal, que se seguiu a um crescimento em solução-tratamento contendo seis diferentes concen trações de alumínio (média de 2 repetições)

\begin{tabular}{|c|c|c|c|c|c|c|c|}
\hline \multirow[t]{2}{*}{ Genótipos } & \multirow[t]{2}{*}{ Genealogia } & \multicolumn{6}{|c|}{ Concentração de alumínio (mg L-1) } \\
\hline & & 0 & 2 & 4 & 6 & 8 & 10 \\
\hline 1 & IAC-24 & 56,5 & 49,7 & 49,7 & 40,9 & 32,7 & 16,0 \\
\hline 2 & IAC-370 & 87,8 & 23,4 & 0,8 & 0,0 & 0,0 & 0,0 \\
\hline 3 & $\begin{array}{l}\text { CEP83121/CEP83140/3/TJB88.1089/ALDAN/ } \\
\text { /CEP13/4/IAC-24 }\end{array}$ & 58,8 & 45,6 & 44,5 & 41,5 & 30,1 & 21,9 \\
\hline 4 & R27/GHL121//KAL/BB/3/BUC/BUL/4/IAC-24 & 65,2 & 29,1 & 46,1 & 43,2 & 29,6 & 3,2 \\
\hline 5 & MAITEN/ /BJY “S” /JUP/3/IAC-24 & 70,8 & 42,5 & 39,3 & 34,2 & 24,9 & 7,1 \\
\hline 6 & GAA "S" / KAUZ "S" / / IAC-24 & 57,7 & 5,2 & 2,0 & 0,0 & 0,0 & 0,0 \\
\hline 7 & GAA "S" / KAUZ "S" / / IAC-24 & 60,2 & 8,0 & 0,7 & 0,0 & 0,0 & 0,0 \\
\hline 8 & OPATA//HAHN*2/PRL/3/IAC-24 & 63,4 & 39,8 & 31,4 & 23,0 & 21,4 & 0,0 \\
\hline 9 & OPATA//HAHN*2/PRL/3/IAC-24 & 54,0 & 0,0 & 0,0 & 0,0 & 0,0 & 0,0 \\
\hline 10 & OPATA//HAHN*2/PRL/3/IAC-24 & 55,3 & 1,0 & 0,0 & 0,0 & 0,0 & 0,0 \\
\hline 11 & OPATA//HAHN*2/PRL/3/IAC-24 & 63,2 & 0,0 & 0,0 & 0,0 & 0,0 & 0,0 \\
\hline 12 & OPATA / /HAHN*2/PRL/3/IAC-24 & 60,3 & 0,0 & 0,0 & 0,0 & 0,0 & 0,0 \\
\hline 13 & OPATA//HAHN*2/PRL/3/IAC-24 & 48,7 & 0,0 & 0,0 & 0,0 & 0,0 & 0,0 \\
\hline 14 & R27/GHL121//KAL/BB/3/BUC/BUL/4/IAC-24 & 65,9 & 51,0 & 47,4 & 46,0 & 33,5 & 11,9 \\
\hline 15 & R27/GHL121//KAL/BB/3/BUC/BUL/4/IAC-24 & 67,5 & 49,3 & 46,4 & 37,0 & 28,8 & 4,4 \\
\hline 16 & R27/GHL121 / /KAL/BB/3/BUC/BUL/4/IAC-24 & 66,6 & 47,9 & 45,3 & 34,8 & 27,8 & 16,1 \\
\hline 17 & R27/GHL121 / / KAL/BB/3/BUC/BUL/4/IAC-24 & 61,4 & 53,2 & 50,2 & 35,8 & 29,6 & 19,3 \\
\hline 18 & R27/GHL121 / / KAL/BB/3/BUC/BUL/4/IAC-24 & 75,2 & 57,9 & 46,4 & 36,5 & 25,8 & 21,8 \\
\hline 19 & MN 91309/IAC 24 & 50,8 & 50,5 & 39,2 & 29,6 & 21,7 & 7,9 \\
\hline \multirow[t]{3}{*}{20} & MN 91309/IAC 24 & 57,0 & 43,0 & 44,2 & 36,2 & 33,2 & 14,3 \\
\hline & BH-1146 & 108,2 & 70,2 & 61,0 & 57,5 & 50,3 & 41,5 \\
\hline & Anahuac & 88,1 & 0,0 & 0,0 & 0,0 & 0,0 & 0,0 \\
\hline
\end{tabular}


Pela correlação entre as médias de produção de grãos e as médias de altura das plantas de cada genótipo, considerando-se os três anos, em cada local separadamente, constataram-se resultados positivos em Capão Bonito $\left(0,94^{*}\right)$ e Tatuí $(0,15)$. Esses dados sugerem que somente em Capão Bonito os genótipos mais altos, isto é, aqueles que tiveram desenvolvimento normal, pouco afetados pela presença de $\mathrm{Al}^{3+}$ no solo, foram os mais produtivos e os genótipos com redução drástica da altura da planta, causada pela alta sensibilidade à toxicidade de alumínio, foram os menos produtivos. Esses resultados foram confirmados levando-se em conta as correlações simples entre as médias de altura das plantas, considerando-se os três anos, em Capão Bonito, e o comprimento médio das raízes em cada concentração de alumínio, contendo $2\left(0,93^{*}\right), 4\left(0,92^{*}\right)$, $6\left(0,90^{*}\right), 8\left(0,89^{*}\right)$ e $10\left(0,69^{*}\right) \mathrm{mg} \cdot \mathrm{L}^{-1}$ de $\mathrm{Al}^{3+}$. As correlações simples entre as médias de altura das plantas considerando-se os três anos, em Tatuí, e o comprimento médio das raízes em cada concentração de alumínio foram: $2\left(0,52^{*}\right), 4\left(0,45^{*}\right), 6\left(0,45^{*}\right), 8(0,40)$ e $10(0,25) \mathrm{mg} \cdot \mathrm{L}^{-1}$ de $\mathrm{Al}^{3+}$. Portanto, as plantas mais altas estavam associadas às plantas mais tolerantes à toxicidade de alumínio, principalmente em Capão Bonito, concordando com os resultados relatados por SALOMON et al., 2003 também estudando o comportamento de linhagens diaplóides em solos ácidos e corrigidos.

\section{CONCLUSÕES}

1. A cultivar IAC-24 e as linhagens diaplóides L3, L4, L5, L8, L14, L15, L16, L17, L18, L19 e L20 destacaram-se quanto à produção de grãos em condição de sequeiro e solo ácido sem aplicação de calcário; em soluções nutritivas, foram as mais tolerantes à toxicidade de alumínio.

2. Em todos os genótipos observou-se porte semi-anão.

3. As linhagens diaplóides L15 e L16, foram resistentes ao acamamento; na cultivar IAC-370, observaram-se espigas mais compridas e maior número de grãos por espiga e por espigueta; na L8 o maior número de espiguetas por espiga e nas L6 e L7, os grãos mais pesados.

4. Todos os genótipos foram suscetíveis à mancha-da-folha.

5. As linhagens L4, L14, L15, L16, L17 e L18 oriundas do cruzamento R27/GHL121 / / KAL/BB/3 / $\mathrm{BUC} / \mathrm{BUL} / 4 / \mathrm{IAC}-24$ foram resistentes à ferrugem-dafolha, podendo ser utilizadas como fontes genéticas em programa de melhoramento visando à resistência ao agente causal dessa doença.

\section{AGRADECIMENTOS}

À Fundação de Amparo à Pesquisa do Estado de São Paulo (FAPESPP) pelo apoio financeiro ao projeto e ao Conselho Nacional de Desenvolvimento Científico e Tecnológico (CNPq) pela concessão de bolsa de produtividade científica.

\section{REFERÊNCIAS}

CAMARGO, C.E. de O. O pH das soluções nutritivas no comportamento de cultivares de trigo à toxicidade de alumínio. Bragantia, Campinas, v.43, n.2, p.327-335, 1984.

CAMARGO, C.E. de O. Trigo. In: FURLANI, A.M.C.; VIÉGAS, G.P. (Eds). O melhoramento de plantas no Instituto Agronômico. Campinas, Instituto Agronômico, 1993. p.433-488.

CAMARGO, C.E. de O.; FELICIO, J.C.; FERREIRA-FILHO, A.W.P.; BARROS, B. de C.; PEREIRA, J.C.V.N.A.; PETTINELLI-JUNIOR, A. Comportamento agronômico de linhagens de trigo no Estado de São Paulo. Bragantia, Campinas, v.60, p.35-44, 2001.

CAMARGO, C.E. de O.; FELICIO, J.C.; FERREIRA-FILHO, A.W.P.; FREITAS, J.G. de; BARROS, B.de C.; CASTRO, J.L. de; SABINO, J.C.; KANTHACK, R.A.D. Melhoramento do trigo: XXIII. Avaliação de linhagens na região do Vale do Paranapanema, em Capão Bonito e em Tietê, em 1984-88. Bragantia, Campinas, v.49, n.1, p.43-67, 1990.

CAMARGO, C.E. de O.; FELICIO, J.C.; FERREIRA-FILHO, A.W.P.; FREITAS, J.G. de; KANTHACK, R.A.D.; BARROS, B.de C. Melhoramento do trigo: XXIV. Avaliação de novos genótipos na Estado de São Paulo. Bragantia, Campinas, v.50, n.2, p.203-223, 1991.

CAMARGO, C.E. de O.; FERREIRA-FILHO, A.W.P. São Paulo State Brazil Wheat Pool. In: BONJEAN, A.P.; ANGUS, W.J. (Ed.). The World Wheat Book: A History of Wheat Breeding. Paris, 2000. Cap. 21, p. 549-577.

CAMARGO, C.E. de O.; FERREIRA-FILHO, A.W.P.; RAMOS, L.C. da S.; PETTINELLI-JUNIOR, A.; CASTRO, J.L. de.; FELICIO, J.C.; SALOMON, M.V.; MISTRO, J.C. Comportamento de linhagens diaplóides de trigo em dois locais do Estado de São Paulo. Bragantia, Campinas, v.62, n. 2, p.217-226, 2003.

CAMARGO, C.E. de O.; FERREIRA-FILHO, TULMANN NETO, A.; PETTINELLI-JUNIOR, A.; CASTRO, J.L. de; FELICIO, J.C.; MISTRO, J.C.; SALOMON, M.V. Avaliação de linhagens de trigo originárias de hibridação com e sem irradiação gama. Bragantia, Campinas, v.64, n.1, p.61-74, 2005.

CAMARGO, C.E. de O.; OLIVEIRA, O.F. de. Tolerância de cultivares de trigo a diferentes níveis de alumínio em solução nutritiva e no solo. Bragantia, Campinas, v.40, p.21-31, 1981. 
CAMARGO, C.E. de O.; RAMOS, L.C. da S.; FERREIRAFILHO, A.W.P.; FELICIO, J.C.; PETTINELLI-JUNIOR, A.; CASTRO, J.L. de.; YOKOO, E.Y. Linhagens diaplóides de trigo: produção de grãos, características agronômicas e tolerância à toxicidade de alumínio. Bragantia, Campinas, v.58, n. 2, p.235-246, 1999.

CAMARGO, C.E. de O.; TULMANN-NETO, A.; FERREIRAFILHO, A.W.P.; FREITAS, J.G. de; PETTINELLI-JUNIOR, A.; CASTRO, J.L. de. Avaliação de genótipos oriundos de cruzamento interespecífico e radiação gama no Estado de São Paulo. Scientia Agricola, Piracicaba, v.52, n.1, p. 25-37, 1995.

CAMARGO, C.E. de O.; TULMANN-NETO, A.; FERREIRAFILHO, A.W.P.; FELICIO, J.C.; CASTRO, J.L. de.; PETTINELLIJUNIOR, A. Novos genótipos de trigo (Triticum aestivum L.) obtidos por irradiação gama. Scientia Agricola, Piracicaba, v.54, n.3, p. 195-202, 1997.

GRANDO, M.F.; MORAES-FERNANDES, M.I.B. Two point deterministic model for acquisition of in vitro pollen grain androgenetic capacity based on wheat studies. Brazilian Journal of Genetics, Ribeirão Preto, v.20, n.3, p.467-476, 1997.

LOBATO, M.T.V.; CAMARGO, C.E. de O.; FERREIRA-FILHO, A.W.P.; BARROS, B. de C.; PETTINELLI-JUNIOR, A.; PEREIRA, J.C.V.N.A.; GALLO, P.B. Desempenho de linhagens de trigo mexicanas, em condição de irrigação por aspersão no Estado de São Paulo. Arquivos do Instituto Biológico, São Paulo, v.72, n.2, p.211-219, 2005.
MEHTA, Y.R. Doenças do trigo e seu controle. São Paulo: Agronômica Ceres, 1978. 190p. (Ceres, 20)

MOORE, D.P.; KRONSTAD, W.E.; METZGER, R.J. Screening wheat for aluminum tolerance. In: WORKSHOP ON PLANT ADAPTATION TO MINERAL STRESS IN PROBLEM SOILS, 1976, Beltsville. Proceedings... Ithaca: Cornell University, 1976. p.287-295.

RAMOS, L.C. da S.; YOKOO, E.Y.; CAMARGO, C.E. de O. Adequação de meios de cultura de anteras e testes de genótipos de trigo. Bragantia, Campinas, v.53, n.2, p.151-157, 1994.

SALOMON, M.V.; CAMARGO, C.E. de O.; FERREIRA-FILHO, A.W.P.; PETTINELLI-JUNIOR, A.; CASTRO, J.L. de. Desempenho de linhagens diaplóides de trigo obtidas via cultura de anteras quanto à tolerância ao alumínio, produção de grãos e altura de planta. Bragantia, Campinas, v.62, n. 2, p.189-198, 2003.

SCHRAMM, W.; FULCO, W.S.; SOARES, M.H.G.; ALMEIDA, A. Resistência de cultivares de trigo em experimentação ou cultivo no Rio Grande do Sul, às principais doenças fúngicas. Agronomia Sulriograndense, Porto Alegre, v.10, n.1, p.31-52,1974.

TULMANN NETO, A.; CAMARGO, C.E. de O.; CASTRO, J.L. de; FERREIRA-FILHO, A.W.P. Evaluation of 'Anahuac' wheat mutant lines for aluminum tolerance. In: MALUSZYNSKI, M.; KASHA, K.J. (Ed.). Mutations: In Vitro and Molecular Techniques for Environmentally Sustainable Crop Improvement. Netherlands, 2002. p.113-120. 